\title{
Ageing Society and Labor Policy in China: Analyzing Policy Challenges and Options
}

\author{
Vaishali Singh \\ Department of East Asian Studies, University of Delhi, Delhi, India \\ Email:vaishali1du@yahoo.com
}

How to cite this paper: Singh, V. (2018). Ageing Society and Labor Policy in China: Analyzing Policy Challenges and Options. Chinese Studies, 7, 242-250.

https://doi.org/10.4236/chnstd.2018.73021

Received: February 15, 2018

Accepted: August 14, 2018

Published: August 17, 2018

Copyright $\odot 2018$ by author and Scientific Research Publishing Inc. This work is licensed under the Creative Commons Attribution International License (CC BY 4.0).

http://creativecommons.org/licenses/by/4.0/

\begin{abstract}
As the defining characteristic of the twenty-first century, global ageing poses some overwhelming demographic questions. The most important challenge comes in the form of the glaring impact of ageing society on the continuous labor supply to sustain the growth momentum. Given the vast size and rapid pace of demographic change, China is one nation facing a humongous policy challenge in the arena of labor and social policy. From retirement policies, older worker discrimination to the strain on social security systems, the range of issues is quite varied. The paper thus looks at the policy challenges and options in framing a prudent labor policy in the light of a rapidly ageing society. In dealing with the policy challenges and learning from international experience, the study makes a comparison with policies in Japan where the concerted efforts by state has resulted in innovative and elderly-friendly work policies. The study finds that managing ageing workforce is the most viable option which requires that policies be rejiggered at state, market and familial level.
\end{abstract}

\section{Keywords}

China, Ageing, Labor Policy, Older Workers

\section{Introduction}

Global ageing is a fact. While Europe and Japan are among the most rapidly ageing societies, population ageing has also emerged as the looming crisis facing public policymakers in the Asia (Feng, 2010). Within the next few decades, Asia is poised to become the oldest region in the world. As the most populated nation, People's Republic of China is faced with meeting the challenge of an ageing society more than any other nation. The benefits of a demographic window of opportunity have been reaped for long. Now the demographic fortune is dwin- 
dling and China faces a huge challenge of coping with the socio-economic costs associated with a large geriatric population. In other words, this presents the predicament of "getting old before getting rich". The demographic transition is driven by falling fertility and rising life expectancy. In case of China, the one-child policy (enforced since late 1970s) combined with improved longevity of the populace has largely been responsible for the demographic transformation towards an ageing society (see Figure 1).

The spotlight is on older workers because a large youthful workforce is giving way to a graying continent where the ratio of retirees to workers is on the rise. According to Reuters, China now has six people in the workforce for every retiree, and this ratio could narrow to 2:1 between 2030 and 2050. And a very small percentage of Chinese have old age income support. A key feature of population ageing is the progressive ageing of older population itself. More and more older people are surviving to even more advanced ages. This creates a vast expansion of demand for health, housing accommodation and pensions for ageing populations and is thus of crucial importance for governments, policy makers, planners, and researchers (Powell \& Chen, 2012). Public policy for an ageing workforce is thus critical in sustaining high growth and bringing about inclusive development.

While the debate on age and ageing is multifaceted, the most blatant impact of an ageing society can be seen on the labor market. In terms of labor policy, a growing older population and the expected decrease in the worker-retiree ratio poses a host of challenges for policymakers such as shrinking pool of young skilled labor; high wage bills; age discrimination in employment; limited pension or healthcare coverage for workers. Apart from the traditional focus on standard of living and retirement concerns, the public policy of ageing may also be influenced by the intersection of class, gender, race and ethnicity, resulting in loss of power, autonomy, and influence of older persons. The problem is compounded by the prevalence of informal employment where workers are usually unprotected by labor regulations and lack access to pensions and other social benefits.

The paper is divided into three main sections. Section I underscores the theoretical setting for understanding the problematique of ageing society in general. Section II points out the policy challenges being faced both by the leadership and the populace in China in the arena of labor and employment. Section III attempts to look at the way forward in terms of policy options including learning from international experience.

\section{The Theoretical Underpinnings of an Ageing Society}

\subsection{Constraint and Choice}

Demographic change in the 21st Century-with the rise of ageing populations across the Global North and South-is setting moral as well as political and economic challenges for the range of countries involved. On one side there are some complex issues about the distribution of resources between generations 


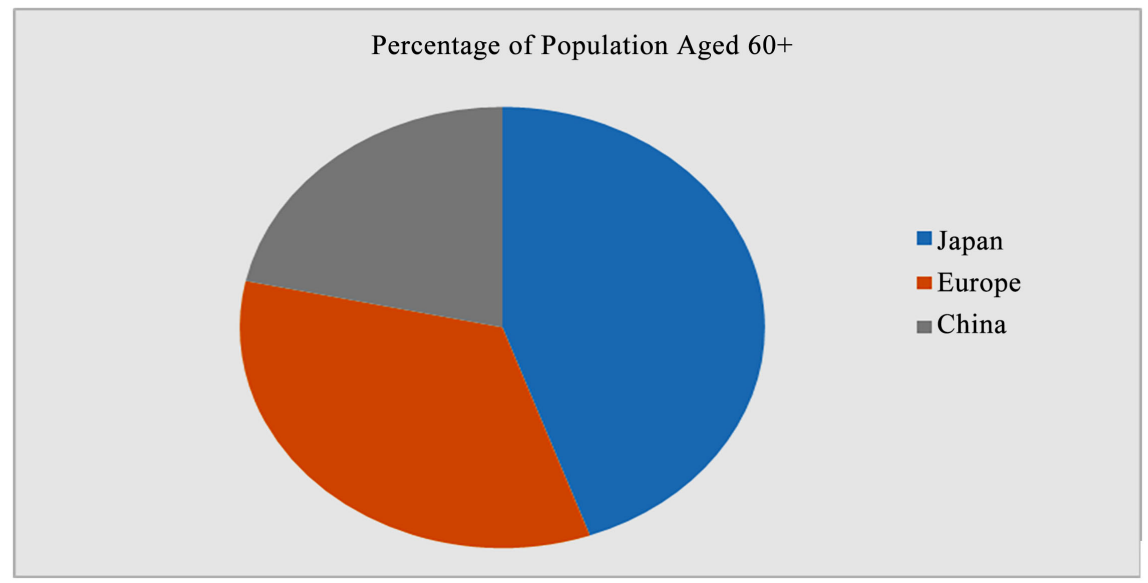

Figure 1. Elderly population in Europe, Japan and China (2017). Source: UN data.

and groups, with pressures placed on the shoulders of individuals in determining how to manage life in old age. On the other side has come a strong sense of the possibilities of new areas of choice in later life, notably with debates around the rise of the so-called "third age" and the growth of leisure and cultural industries targeted at older people. Thus there are two sides to growing old-constraint on the one side and choice on the other.

\subsection{Ageing as a Contingent Limitation}

The problem of an ageing society suffers from reductionist tendencies and there is need to distinguish between contingent and existential limitations (Baars, Dohmen, Grenier, \& Phillipson, 2013). The contingent limitations are neither inherent in human life nor inevitable in senescing, such as poor housing conditions, insufficient care, social isolation, starvation or ageism. They may be the result of lack of knowledge, the unintended consequences of certain policies or caused by a lack of interest or respect for the well-being of older people (Baars, Dannefer, Phillipson, \& Walker, 2006). The existential limitations, however, are vulnerabilities that are inherent in human life and that will inevitably manifest themselves as people live longer. When all limitations are seen as existential, ageing people have to accept all circumstances, however dreadful. However, when all limitations are seen as contingent limitations-a commercial tendency of late modernity-the illusion develops that one should not have to accept any limitation, that any problem can be solved given the time, money, and the determination to do it (Grey, 2005).

\section{Policy Challenges}

\subsection{To Work or Not to Work in Old Age}

The issue of work and retirement is a thorny one. Some people are forced to retire because of age discrimination or because of illness. Others must continue to work, often at menial jobs, because they cannot afford to retire. Further, the economics of supply and demand govern one's presence in or out of the job 
market. If there is a demand for your work, you stay; if there is not, you are encouraged to retire (Hillier \& Barrow, 1999). Self-concept is closely tied to life's work. Retirees may feel either elated and free or devalued and depressed. For some people retirement is a welcome respite after many years of work. For others it is a loss of daily companionship, income, and meaningful activity.

From a policy perspective, it is important to understand that the development level of the economy, the socio-cultural norms regarding age, and the preferences of political actors all play into the framing of retirement rights. The policy trend in most ageing societies has tended to favor late retirement to offset any labor shortage and gives little regard to individual preferences on early retirement. However, there is a growing concern among workers that they might not be able to enjoy the fruits of working a lifespan if they retire very late. Most are wary of "work till you drop" and do not wish to miss out on a comfortable retired life.

\subsection{Older Worker Discrimination}

The big question is-does age make a predictable, negative difference in job performance? Early retirement needs to be voluntary. But defining a voluntary will to retire is itself problematic. Do you leave of your own free will if your boss drops hints that you are not wanted and hints at a big bonus offer if you leave early? Or if you are told that in a year your job will be phased out?

Ageism in the labor market is an issue that is deeply ingrained both institutionally and culturally. As a phenomenon, ageism occurs in all kinds of job categories without gender discrimination. Ageism is most prominently manifest in layoffs. Studies have demonstrated that the unemployed people regard age to be a significant variable in explaining their layoffs. Once out of work, older workers are likely to remain unemployed for a longer period than their younger counterparts. If they do find work, it is usually at a much lower salary and with fewer fringe benefits (Hillier \& Barrow, 1999).

On-the-job discrimination is mostly fueled by negative stereotypes of older workers. Workers after a certain age are thought to be accident-or illness-prone, to have a high absenteeism rate, to have a slow reaction time, to be difficult to train, to lack drive and imagination, and that they are averse to change and grouchy in behavior.

\subsection{Worker to Non-Worker Ratios-A Strain on Social Security Systems}

Social security operates on the principle of sharing. While some die before they are able to collect benefits, others live long enough to get back much more than they contributed. The ledger apparently balances. However, the situation is changed now. The increasing percentage of elders and their increasing life expectancy has greatly strained the social security system. The number of active taxpayers supporting the retirees has been decreasing at a rapid rate. With Chi- 
na's working age population registering a decline, speculations have arisen surrounding the end of "Cheap China" and increase in wage pressures. Since, China is still grappling with the issue of poverty and inequality as a result of its focus on unbridled growth, the country's system is still not fully prepared to sustain the social security needs of a large geriatric population. In other words, pervasive corruption and shrinking tax base pose formidable challenges before policymakers in terms of coalescing resources required for meeting the imminent social security challenge.

\subsection{Retaining Older Workers: How to Motivate the Private Sector?}

James H. Schulz in "The Economics of Ageing" has underlined that while private pensions have become more widespread over the years, private plans still fail to cover many people who work for small businesses; the uncovered are also more likely to be non-union, female, part time, lower paid, and in the trade or service industries (Schulz, 2001).

Marty Denis has analyzed the rationale of business and industry in initiating early retirement incentive programs (ERIPs). He lists six advantages of early retirement from a corporate perspective. 1) They can reduce the need for massive layoffs 2) payroll costs can be reduced 3) the number of senior, more highly paid employees can be reduced. 4) When done across-the-board (not targeted), employee morale may be preserved or at least not unduly disrupted. 5) Because of the release component, employment discrimination claims can be minimized, if not avoided. 6) Promotion channels can be opened so that other qualified employees can advance within the company (Denis, 1996).

\subsection{Problems with Pensions: Lack of Comprehensiveness}

There are a number of gaps in the coverage of private pension plans. Temporary or part-time employees do not typically have a pension plan offered by their employers. Some have no pension plan at all while others require an employee to have served for some years before availing pension benefits.

In case of China, the implicit potential support ratio was 6 in 2005, but will rapidly decline to 2 by 2040 (Leckie, 2011). A 2005 World Bank study estimated that under a baseline scenario with the current pension system, the PRC's implicit pension debt amounted to approximately $140 \%$ of its GDP, with a financing gap of as much as $95 \%$ of GDP. In 2000, the Chinese government established the NSSF as a "strategic reserve fund" and a solution to the problem of ageing under the supervision of the National Council for Social Security Fund (NCSSF), a ministerial level entity directly reporting to the State Council.

The rural-urban disparity also afflicts and gets afflicted by the challenge of ageing society. Social security for the rural population has always been lagging behind their urban counterparts. Understanding that rural pension system is the key to narrow the gap between rural and urban standards of living, the Chinese 
government launched the new rural pension system in 2009.

However, there are certain limitations in the present pension system in China. There is a need to improve participation, coverage, and transparency of pension funds. The level and extent of investment and contributions also needs to be augmented.

\section{The Way Forward: Policy Options}

The China Health and Retirement Longitudinal Study (CHARLS) of National School of Development in Peking University have been actively researching on the issue of ageing in China. In a survey conducted in 2013, it was highlighted that $32 \%$ of elderly Chinese reported having poor health, $38 \%$ said they were disabled, $23 \%$ are below the poverty line and $40 \%$ show symptoms of depression. The report recommended that only if policy changes can support efforts by the elderly to migrate to where children live, then children can remain economically active while caring for their parents (National School of Development, Peking University, 2013).

Broadly, there are two sides to the debate on how to meet the challenge of ageing workforces. On one side are the proponents of early retirement or flexible retirement who claim this would usher in a new era of opportunities, a golden age of job openings. On the other hand, prolonging working lives emerges as a viable option. The rationale is that working lives need to be extended if social welfare systems are to be sustainable and there is to be an adequate supply of labor going forward. By utilizing measures involving additional work incentives for older workers and women and raising the propensity of youth to combine work and education, it will be possible to mitigate or offset adverse demographic effects.

In dealing with effects of ageing on labor, the European Union taskforce on employment submitted a report to the European Council in 2003 highlighting three key measures-1) Provide incentives for workers to retire later and for employers to hire and keep older workers; 2) promote access to training for all regardless of age and to develop life-long learning strategies; and 3) to improve the quality of work to provide attractive, safe and adaptable work environment throughout the working life, including the provision of part-time work and career breaks (Kok, 2003).

The Australian Council on Ageing underscores a five-point strategic plan-1) maintaining economic growth to generate sufficient jobs, combined with effective labor force management; 2) tackling age discrimination; 3) providing adequate opportunities for learning and training; 4) flexible jobs and social security provision; and 5) an adequate safety net for those unable to work (Andrews, 2001).

A significant development in the discourse on the policy issue of ageing society is the Active Ageing Policy Framework. The concept being promoted is "Active Ageing" i.e. the process of optimizing opportunities for health, partici- 
pation and security in order to enhance quality of life as people age. It is a call to action for policymakers and provides a roadmap for designing multi-sectoral active ageing policies which will enhance health and participation among ageing populations while ensuring that older people have adequate security, protection and care when they require assistance.

\section{Learning from International Experience: Case of Japan}

In the changing demographic landscape around the world, the ageing society in China is more often compared to the similar phenomenon in Japan. Such a view is frequently accompanied by a warning that although the greying population is not as acute as Japan's, down the track, China may well be poised to face challenges that Japan is grappling with. Despite the introduction of two-child policy on a nationwide scale in 2015, the birth rates have not risen as expected. In a survey in Beijing, the All-China Women's Federation found that as much as 53 per cent of respondents having one child did not wish to have a second child (China Daily, 2016). Quite like Japan, the low birth rates are cutting into the supply of potential workers in China. A common macro-trend in China and Japan with regard to ageing societies and labor policy is the realignment of job market currently underway to fill the labor-deficits. There is a widespread recognition of the need to prolong working years, admit immigrants, and automate more jobs (METI, 2017). The primary difference between Japan and China in terms of ageing of population lies in the timing of this phenomenon. China, as mentioned before, is uniquely placed with the ageing of population landing much earlier and at much lower level of development. However, Chinese state has been conditioning to such change in a gradual manner and the experience of Japan can serve as a valuable guide to policymakers in dealing with labor policy.

The Japanese government has implemented various employment policies, to actualize "a society where people can work until 70 years of age." The policymakers aim has been to 1) promote employment of older adults 2) support and facilitate re-employment of mid-life and older workers, and 3) facilitate diverse employment and social participation of older adults. In 2002, labor laws concerning older persons were amended and now require employers to take steps to modify their existing employment procedures. A host of policies have also been introduced to provide older workers who were unemployed with services to promote re-employment. The law concerning stabilization of employment of older persons stipulates that, regardless of size, companies 1) abolish the retirement age 2) raise the retirement age to 65 , or 3 ) implement a system to rehire workers when they retire at age 60 . The government provides grants 1) to help employers expand new job categories, 2) improve work conditions and enable older workers to work up to or beyond the age of 70,3) raise the retirement age to 65 or above, and 4) introduce a continual employment system for workers who wish to continue working (Japan Organization for Employment for the Elderly and Persons with Disabilities, 2006). The government also established the 
Silver Human Resource Center (SHRC), which provides community-based employment services for employment and skills training, as well as job matching services. Various innovative initiatives such as telecommuting and work sharing are also emerging in both public and private sectors.

In case of Japan, economic conditions determine the high employment rates among older Japanese. To prolong the working lives of older workers, policymakers in Japan have increased the eligibility age for full public pension benefits from the National Pension Plan (NPP). The Japanese culture that values work over leisure is also responsible for high labor participation among the elderly. While a typical Western concern is "when can I retire?" the Japanese are more concerned with "how long can I work?" (Shibusawa \& Kidahashi, 2012). For Japanese elders, work is closely tied to the notion of ikigai, defined as something that gives meaning to one's life.

However, the Japanese example shows that companies usually choose to rehire employees rather than abolish mandatory retirement or extend the retirement age to 65 (Takagi, 2009). This is not in line with the wishes of older workers as when rehired they are treated differently from regular workers, and their income drops as much as by 56 percent (Fujimoto, 2008). In addition, there have been some cases in which companies have knowingly given rehired older workers tasks that are beyond their physical capacity, effectively forcing them to retire (Oka, 2009). Furthermore, many older workers feel marginalized and feel their skills and knowledge are no longer fully utilized (Takahashi, 1996). There is a need to find out ways to address and balance the needs of workers and the company's desire to enhance market competitiveness.

\section{Conclusions}

Population ageing and the so-called looming crisis facing policy makers is a pertinent concern. At the heart of the issue lies the challenge of policy making which is prudent and addresses the question of whether older workers can look forward to the prospect of longer working lives with choice and security and make successful transitions to non-work. In the specific situation of PRC, the paper finds that state capacity is going to be crucial in implementing policies and programs that are tailored to the unique circumstances. Policy responses may require pragmatism and at times new and novel initiatives as it is not certain that labor markets will adjust easily or willingly to the ageing of industrialized society.

Within the institutional framework of policy analysis, apart from the state, the market and the family also emerge as important entities in managing ageing workforces. In other words, ageing is a complex and pervasive phenomenon, with pros and cons, with risks and opportunities. The consequences of this phenomenon as a policy issue will largely depend on the arrangements that the state, the market, and the family will set up and how quickly and effectively these arrangements will adapt to the changes that await us. 


\section{Conflicts of Interest}

The authors declare no conflicts of interest regarding the publication of this paper.

\section{References}

Andrews, K. (2001). National Strategy for an Ageing Australia. Commonwealth of Australia.

Baars, J., Dannefer, D., Phillipson, C., \& Walker, A. (Eds.) (2006). Ageing, Globalization, and Inequality: The New Critical Gerontology. Amityville, NY: Baywood Publishing.

Baars, J., Dohmen, J., Grenier, A., \& Phillipson, C. (2013). Ageing, Meaning and Social Structure: Connecting Critical and Humanistic Gerontology. UK: Policy Press. https://doi.org/10.1332/policypress/9781447300908.001.0001

China Daily (2016). Half of One-Child Families Do Not Want Second Child: Survey. http://www.chinadaily.com.cn/china/2016-12/22/content_27749409.htm

Denis, M. (1996). Implications of Offering Early Retirement Benefits in Exchange for a Release from Employment Claims. Employment Relations Today, 23, 65-69. https://doi.org/10.1002/ert.3910230308

Feng, W. (2010). China's Population Destiny: The Looming Crisis. Brookings Institution.

Fujimoto, M. (2008). Employment of Older People after the Amendment of the Act on Current State of Affairs and Challenges. Japan Labor Review, 5, 59-88.

Grey, D. (2005). Foreseeable and More Distant Rejuvenation Therapies. In Rattan, S. (Ed.) Ageing Interventions and Therapies. Singapore: World Scientific Publishing. https://doi.org/10.1142/9789812701329_0018

Hillier, S., \& Barrow, G.M. (1999). Ageing, the Individual and Society. London: Wadsworth Publishing Company.

Kok, W. (2003). Report of the Employment Taskforce. Brussels: European Council.

Leckie, S. H. (2011). The People's Republic of China: Pension System Overview and Reform Directions. In D. Park, (Ed.), Pension Systems and Old-Age Income Support in East and Southeast Asia: Overview and Reform Directions. London, New York: Routledge.

METI (2017). Transformation: A Foundational Study on Aging in Japan and China. Tokyo: Ministry of Economy, Trade, and Industry.

National School of Development, Peking University, CHARLS Research Team (2013). Challenges of Population Ageing in China: Evidence from the National Baseline Survey of the. China Health and Retirement Longitudinal Study. Beijing.

Oka, M. (2009). Older Workers in Japan: Current Situation and Future Challenges. Kanto Gakuin University. Economics Bulletin, 238, 30-46.

Powell, J. L., \& Chen, S. (2012). The Global Dynamics of Ageing. New York: Nova Science Publishers.

Schulz, J. H. (2001). The Economics of Ageing. London: Auburn House.

Shibusawa, T., \& Kidahashi, M. (2012). Work and Later Life in Japan: In Search for New Directions. In J. Powell \& S. Chen, (Eds.), The Global Dynamics of Ageing. New York: Nova Science Publishers.

Takagi, T. (2009). Koreishya no shuugyou to intai (Employment and Retirement of Older Adults). Japanese Labor Research Journal, 30-42.

Takahashi, Y. (1996). Recent Trends and Strategies for Suicide Prevention in Japan. In R. F. Ramsay \& B. L. Tanney, (Eds.), Global Trends in Suicide Prevention. Mumbai: Tata Institute of Social Sciences. 